\title{
Does India need ministry of public health? - Lessons learnt from COVID-19 and road ahead
}

\author{
Ravinder Singh \\ Division of Noncommunicable Diseases, Indian Council of Medical Research, New Delhi
}

\section{KEY WORDS}

AYUSH

Coronavirus

COVID-19

Disaster

Epidemic

Public Health

*Corresponding Author:

Ravinder Singh, PhD

Scientist, Division of Noncommunicable Diseases

Indian Council of Medical Research

New Delhi

Contact no: +919212112500

E-mail: ravinders.hq@icmr.gov.in
World over there has been debates on the current emergency of COVID-19 and where we failed? Comparing the Spanish Flu 1918 (1) and the COVID-19, it is clear that the prevention strategies like social distancing, hand washing, and mask use, remains only hope for fast-spreading emergencies or disasters like COVID-19 (2). As compared to Spanish Flu-1918, population density is more now and people move across the globe much faster due to the vast network of air travel, posing greater risk to exposed populations. Even today, the challenge remains the lack of vaccines, shortage of appropriate equipment, and healthcare manpower. The basic role of the World Health Organisation and Alma Ata Declaration 1978 was strengthening primary and preventive care by the year 2000 (3). However, the world supported technology to the extent that now we are left with the only option to lockdown city after city across more than 200 counties.

India looked at the options of strengthening of the health system but tilted towards lop-sided crowding of tertiary care in urban areas and all-round neglect of health system in rural areas, where more than $70 \%$ of its population resides. Some of the thinkers suggested segregating healthcare services, health research, and public health as independent but interrelated pillars of people's health (4).

\section{International Models of COVID-19 Management}

Most of the developed countries like Australia, United Kingdom and group of countries like European Union, deal with public health issues through specific legal frameworks.
National Health Security Act 2007 enacted by Australia is used for prevention of health emergencies (5). Within country, Western Australia involves communities in decisionmaking through a participatory approach. Health emergencies in United States are dealt under Public Health and Service Act. Spread of infectious diseases is prevented through same law called the Public Health and Service Act (US Department of Health and Human Services-DHHS) of United States. It lays down specific guidelines to assist states during emergencies and endemics/pandemics (6). WHO's International Health Regulations, 2005 are basis for the EU Decision 1082/13 (7). This decision is a vital legal instrument which enforces the states (countries) to take action during threats to health (8).

In the wake of current pandemic in Spain, all private hospitals have been nationalized. Potential patients are tested using robust mechanism by South Korea. They have also adopted an IT-based strategy to fight coronavirus. Large numbers of isolation centers were created by Malaysia. The public health laws brings in regulatory framework using innovative mechanisms and good clinical practices to the health sector. Public health does not limit itself to prevention, promotion or prediction; but it also uses principles of primary, secondary, and tertiary prevention.

\section{Need for the Ministry of Public Health}

India invoked colonial era Epidemic Diseases Act, 1897 to fight coronavirus (9). With advanced technologies in our hand in 2020 , it is easier to contain pandemic like coronavirus today. We only need a new and robust public health law to empower 
communities based on principles of prevention, promotion, prediction, diagnostic, and primary-secondary-tertiary prevention.

Although National Disaster Management Guidelines, 2008 were used at the national level by Ministry of Health and Family Welfare, but there are some basic differences in disasters and pandemic, which require different management approach (10). These guidelines do help the government to manage epidemic or biological terrorism as an advisory not legal framework.

To combat the coronavirus pandemic, Maharashtra government brought out the Maharashtra COVID-19 Regulations, 2020 (11). Clear instructions were given to identify cases to all government and private hospitals for having separate corners and screening procedures. Health and the district administration are supposed to coordinate with the state integrated diseases surveillance programme (IDSP). Information hygiene must be used by all persons, institutions and organisation through print, electronic or social media and no information to be shared without verification and without prior clearance of the commissioner.

Delhi government also took steps similar to Maharashtra government and passed Delhi Epidemic Diseases, COVID-19 Regulations, 2020 (12). Delhi Epidemic Disease Regulations has been drafted on the pattern of Epidemic Diseases Act, 1897. Like many states in India, the Kerala notified and enacted an Epidemic Ordinance, 2020 (13). The Ordinance has unified and consolidated all laws related prevention of epidemic diseases. Such steps are significant to enthuse confident among the citizens and are effective steps towards prevention and control of novel coronavirus infection. Among various sections, the Section 2, sub-section (a-j) clearly mentions and direct government to undertake measures like sealing of state borders, physical distancing, banning travel and controlling working environments. There are provisions of penalty for violations of the restrictions as per this ordinance. A persons can be sent to prison for two years or a fine of Rs.10,000, or both, if there is any violation. These ordinances can be seen as an extension of historical Epidemic Diseases Act. But we need a structured and holistic public health law, which includes the principles of modern and ancient sciences. There are no particular provisions or any framework to address a COVID-19like public health situations.

The bills like National Health Bill, 2009 (14), and the Public Health (Prevention, Control and Management of Epidemics, Bio-terrorism and Disasters) Bill 2017 (15) were proposed, but unfortunately, these Bills lapsed due to various issues raised earlier.

India also proposed and drafted a National Health Policy, 2017. The principles of prevention and promotion were main target areas under this policy. It was thought that policy will be helpful in identification of existing gaps. The policy was an effort to shift the focus from current curative services through tertiary care centres to community based prevention and promotion activities. The gaps as visible make a strong case for comprehensive public health law through a dedicated agency. Such agency is lacking in India. We may need to relook at National Health Policy, 2017 from the perspective of COVID-19 and epidemic diseases. Proper policy directions through enactment and revision of the existing legal instruments should be the target of National Health Policy. Century old Epidemic Act, 1897 should be revised or upgraded in light of advancements in research, healthcare services and technology development. Different laws related to public health should be integrated for strengthening community response, disaster management, food \& nutrition security, and environmental interventions. Public Health angles and impacts of water pollution, noise pollution, and environment should be addressed by a comprehensive law. Special section on sanitation and hygiene should be mentioned, which may include physical distancing, hand hygiene etc. This becomes important under present situation like coronavirus outbreak. Detailed guidelines on physical distancing should be widely disseminated through print and electronic media.

Government of India formed the Ministry of AYUSH on 9th November 2014. The aim was to ensure appropriate placement of AYUSH systems within overall health care system of Inida (16). Previously, the Department of Indian System of Medicine and Homeopathy (ISM\&H), was under Ministry of Health and Family Welfare (MoHFW). The Department of ISM\&H was created in March 1995. In November 2003, it was renamed as Department of Ayurveda, Yoga and Naturopathy, Unani, Siddha and Homoeopathy (AYUSH). Most of these 'pathies' have strong role in prevention of diseases and promotion of health, which has been neglected in modern medical sciences dominating our health system currently. In view of the 'social' distancing and suggestion of Ministry of AYUSH for immunity enhancing diets, it has become very clear that all the specialities under Ministry of AYUSH have strong component of prevention-promotion as relevant to public health. Role of Ministry of AYUSH can be further strengthened and broadened by converting it into Ministry of Public Health.

Similar views were raised earlier where an integrated healthcare system was proposed. There is need for change in the structures of medical colleges like allopathic, ayurvedic, homeopathic, dental, and naturopathy. This should be 'transformational change', not just an incremental change. A basic medical degree may be considered combining physical health, social, spiritual, mental and therapeutic components of healthcare system (integration at ministry level and college level). These basic doctors shall be closer to communities. Being holistic in approach, their main focus will be preventive and promotive aspects of health. They would be instrumental in delivering integrated solutions by combining modern medicine, alternative medicine, diet, behaviour, naturopathy, and yoga. Simpler solutions are possible with public health measures like Swach Bharat Abhiyan (the clean India campaign). These are proven strategies which may result in eradication or minimization of communicable diseases like coronavirus infection (17).

\section{Way forward}

A dedicated public health law is the need of the hour in view of the pandemic like coronavirus. A laws which is all-inclusive 
and comprehensive. India may revise the Public Health Bill 2009 and reintroduce it as a robust public health strategy for creation of separate Ministry for Public Health. This should lay down the foundation of new era for launching Ministry of Public Health. The finer details can be shared once the concept is agreed by top echelons of the power. Ministry of Public Health will have community settings as field areas of work rather than lop-sided tertiary care centres. The focus of such a Ministry will be promoting healthy lifestyles in the communities so that in future any epidemic like COVID-19 can be managed easily. Similar recommendations have been given earlier to have an integrated healthcare systems by segregating best working treatment and prevention modalities from all the systems covered under AYUSH.

\section{References}

1. Taubenberger JK. The origin and virulence of the 1918 "Spanish" influenza virus. Proc Am Philos Soc. 2006 Mar;150(1):86-112. PMID: 17526158; PMCID: PMC2720273. As accessed on April 15, 2020.

2. Tomes N. "Destroyer and teacher": Managing the masses during the 1918-1919 influenza pandemic. Public Health Rep. 2010 Apr;125 Suppl 3(Suppl 3):48-62. doi: 10.1177/00333549101250S308. PMID: 20568568; PMCID: PMC2862334. As accessed on April 15, 2020.

3. https://www.who.int/publications/almaata_declaration_en.pdf as accessed on April 15, 2020

4. https://theirishbalance.com/2019/04/04/the-pillars-of-public-healthprotection-prevention-and-promotion/ as accessed on April 15, 2020.
5. https://www.legislation.gov.au/Details/C2016C00847 as accessed on April 18, 2020

6. https://www.phe.gov/Preparedness/planning/authority/Pages/default aspx as accessed on April 18, 2020.

7. https://eur-lex.europa.eu/legal-content/EN/TXT/?uri=CELEX\%3A32013D1082 as accessed on April 18, 2020.

8. https://www.who.int/ihr/finalversion9Nov07.pdf as accessed on April $18,2020$.

9. https://indiacode.nic.in/bitstream/123456789/10469/1/the_epidemic_diseases_act\%2C_1897.pdf as accessed on April 18, 2020.

10. https://ndma.gov.in/en/ndma-guidelines.html as accessed on April 18, 2020.

11. http://www.iitb.ac.in/sites/default/files/CoronaRegulationNotification. pdf as accessed on April 18, 2020.

12. http://health.delhigovt.nic.in/wps/wcm/connect/146af7004d87f91c96a2f 7982ee7a5c7/Epedimic+Act.pdf?MOD=AJPERES\&lmod $=762064770 \&$ CACHEID=146af7004d87f91c96a2f 7982ee7a5c7 as accessed on April 18, 2020.

13. http://dhs.kerala.gov.in/wp-content/uploads/2020/03/bule_23032020. pdf as accessed on April 18, 2020.

14. https://www.ncbi.nlm.nih.gov/pmc/articles/PMC2812745/ as accessed on April 18, 2020

15. https://www.prsindia.org/uploads/media/draft/Draft $\% 20$ PHPCM $\% 20$ of $\% 20$ Epidemics, $\% 20$ Bio-Terrorism $\% 20$ and $\% 20$ Disasters $\% 20$ Bill,\%202017.pdf as accessed on April 18, 2020.

16. http://main.ayush.gov.in/about-us/about-the-ministry as accessed on April 18, 2020.

17. Singh R: Integrated Healthcare in India - A Conceptual Framework. Ann Neurosci 2016;23:197-198. doi: 10.1159/000449479https://www. karger.com/Article/FullText/449479 as accessed on April 18, 2020.

doi: 10.38205/imcr.010201 